\title{
German Shepherd Dog
}

National Cancer Institute

\section{Source}

National Cancer Institute. German Shepherd Dog. NCI Thesaurus. Code C53753.

The German Shepherd Dog is also known as the Alsatian. It is well proportioned and very strong. The coat most often comes in black with tan, sable or all black. It has a sturdy, muscular, slightly elong ated body with a light but solid bone structure. It has round feet with very hard soles. Height: 22-26 inches (55-65 cm.) Weight: 77-85 pounds (35-40 kg.) 